\title{
Differential regulation of morphology and stemness of mouse embryonic stem cells by substrate stiffness and topography
}

\author{
Dongyuan Lü, Chunhua Luo, Chen Zhang, Zhan Li, Mian Long* \\ Center of Biomechanics and Bioengineering and Key Laboratory of Microgravity (National Microgravity Laboratory), Institute of Mechanics, \\ Chinese Academy of Sciences, Beijing 100190, China
}

\section{A R T I C L E I N F O}

Article history:

Received 20 December 2013

Accepted 27 January 2014

Available online 14 February 2014

\section{Keywords:}

Stiffness

Topography

Stem cell

Stemness

Morphology

\begin{abstract}
A B S T R A C T
The maintenance of stem cell pluripotency or stemness is crucial to embryonic development and differentiation. The mechanical or physical microenvironment of stem cells, which includes extracellular matrix stiffness and topography, regulates cell morphology and stemness. Although a growing body of evidence has shown the importance of these factors in stem cell differentiation, the impact of these biophysical or biomechanical regulators remains insufficiently characterized. In the present study, we applied a micro-fabricated polyacrylamide hydrogel substrate with two elasticities and three topographies to systematically test the morphology, proliferation, and stemness of mESCs. The independent or combined impact of the two factors on specific cell functions was analyzed. Cells are able to grow effectively on both polystyrene and polyacrylamide substrates in the absence of feeder cells. Substrate stiffness is predominant in preserving stemness by enhancing Oct-4 and Nanog expression on a soft polyacrylamide substrate. Topography is also a critical factor for manipulating stemness via the formation of a relatively flattened colony on a groove or pillar substrate and a spheroid colony on a hexagonal substrate. Although topography is less effective on soft substrates, it plays a role in retaining cell stemness on stiff, hexagonal or pillar-shaped substrates. mESCs also form, in a timely manner, a 3D structure on groove or hexagonal substrates. These results further the understanding of stem cell morphology and stemness in a microenvironment that mimics physiological conditions.
\end{abstract}

(c) 2014 Elsevier Ltd. All rights reserved.

\section{Introduction}

Pluripotency or stemness maintenance is a basic process that occurs in early embryogenesis and is an important part of stem cellbased therapy. The role of biochemical regulation in preserving the stemness of mouse embryonic stem cells (mESCs) has been widely investigated. For example, co-culture with feeder cells [1-3] such as mouse embryonic fibroblasts (MEFs) [4-6] or their conditioned medium [7-10] has positive effects on mESCs self-renewal and fate control. Leukemia inhibitory factor (LIF), a growth factor involved in the propagation of undifferentiated mESCs, is required to retain the stemness of mESCs [11-13], and the withdrawal of LIF reduces

Abbreviations: CM, conditioned medium; EBs, embryoid bodies; ECM, extracellular matrix; KSR, knockout serum replacement; LIF, leukemia inhibitory factor; MEFs, mouse embryonic fibroblasts; mESCs, mouse embryonic stem cells; MSC, mesenchymal stem cells; NEAA, nonessential amino acids; PA, polyacrylamide; PDMS, poly-dimethylsiloxane; PLGA, poly(lactic-co-glycolic acid); PS, polystyrene; $\mathrm{RFI}$, relative fluorescent intensity; 2D, two-dimensional; 3D, three-dimensional; 2 ME, beta-mercaptoethanol.

* Corresponding author. Fax: +86 1082544131.

E-mail address: mlong@imech.ac.cn (M. Long). expression of the Nanog gene (a marker of inner cell mass and undifferentiated mESCs) on various substrates [14,15]. Matrigel, an alternative substance that may avoid the potential sideeffects of feeding cells or their conditioned medium, is extensively used to manipulate the self-renewal of mouse or human ESCs and induced pluripotent stem cells (iPS) [16,17]. Nevertheless, maintaining an undifferentiated mESCs culture is still difficult for the global population of mESCs, particularly when the expression of Yamanaka factors and Nanog suggest dynamic heterogeneity within distinct sub-populations of single cells [18]. For therapeutic purposes, maintaining a large-scale collection of pluripotent ESCs is a major challenge, and the application of feeder- or serum-free medium is required to protect against immunogenicity from terminally differentiated cells.

In addition to the biochemical regulators, biophysical or biomechanical cues are also crucial for maintaining stem cell stemness. Stiffness of the substrate or stem cell itself is one of most frequently tested factors. For example, mESCs cultured on soft polyacrylamide (PA) hydrogel substrates retain their stemness by generating homogeneous undifferentiated colonies, presenting with high levels of Oct3/4 and the Nanog biomarker, and efficiently forming embryoid bodies (EBs) and teratomas [19], exerting low 
cell traction forces on the soft PA substrate [20]. This observation is further confirmed by the fact that the size and number of mESC EBs are reduced when they are placed on soft polydimethylsiloxane (PDMS) bi-layer substrates with different stiffness but the same surface chemistry [21]. By contrast, rigid substrates promote the induction and differentiation of cardiomyocytes while mESCderived cardiac foci display functional synchrony with native cardiomyocytes [22]. Stemness preservation is also attributed to the low elastic modulus of undifferentiated mESCs placed on a stiff tissue culture dish compared to that for differentiated mESCs [23]. On the other hand, external mechanical stimuli can also manipulate mESC stemness. Cyclic mechanical strain attenuates the reduction of Nanog expression of mESCs after LIF withdrawal [24]. By combining an optical stretch assay with fluorescence recovery after photobleaching and histone modification analyses, naïve mESCs were found to have significantly stiffer nuclei in a condensed chromatin state; however, naïve mESCs decondense their chromatin by down-regulating the pluripotency marker Nanog before they initiate lineage commitment [25]. For large-scale expansion in a stirred or perfused bioreactor, mESCs can retain their stemness with proper biomechanical control of the shear stress and nutrient supply [26]. Thus, the role of biomechanical or biophysical factors in maintaining stemness in ESCs is deserving of more attention.

Physiologically, the stem cell niche physically anchors stem cells, via adhesive molecules such as integrins or cadherins, to extracellular matrix (ECM) substrates in a three-dimensional (3D), topographical structure at different tissue sites. Both substrate stiffness and substrate topography are potential regulators of stem cell self-renewal and fate. The substrate topography is critical to the induction and maintenance of various cellular functions. mESCs are exquisitely sensitive to mechanical cues at the topographic micro/nano-scale. Distinct types of topographical patterns and dimensions, along with differences in physical characteristics such as roughness, height, spacing, and distribution, play roles in controlling mESCs on the substrate. The combination of an electrospun poly(lactic-co-glycolic acid) (PLGA) scaffold with nano-scaled roughness and matrigel has a synergistic effect on pluripotency maintenance of undifferentiated, feeder-free mESCs with high expression of stemness markers [27]. mESC stemness is better retained when cells adhere to cross-linked PLL/HA films but not to native films, which suggests that nanoscale control plays a key role in the substrate surface chemistry [28]. A micropatterned PA hydrogel with circle dots is a reasonable substitute for MEF feeders in mESC stemness maintenance; in fact, the co-expression of different markers is even better on a hydrogel than on matrigel culture in distinct sub-populations of cells [18]. To date, few studies have investigated how substrate topography, individually or in combination with substrate stiffness, modulates the self-renewal and fate of mESCs. The underlying mechanisms behind biomechanical regulation are poorly understood. In this study, we tested the impact of three types of topographical PA substrates, with two distinct elasticities, on mESCs stemness maintenance. Differential morphological changes and pluripotent marker expressions were analyzed and discussed.

\section{Materials and methods}

2.1. Construction of biopolymer substrates

Topographical substrates were constructed using PA hydrogel via a soft-contact lithography technique described in our previous work [29]. Briefly, $10 \mathrm{ml}$ of $40 \%$ acrylamide and $2 \%$ bis-acrylamide were mixed in water to form a solution with a constant concentration of $10 \%$ acrylamide and two with concentrations of 0.03 and $0.30 \%$ bis-acrylamide. By adding $1 / 200(\mathrm{v} / \mathrm{v})$ of $10 \%$ ammonium peroxydisulfate (curing agent) and $1 / 2000(\mathrm{v} / \mathrm{v})$ of $N, N, N^{\prime}, N^{\prime}$-tetramethylethylenediamine (accelerating agent) into the mixture, the designed mask for the desired planar or topographical configuration was suspended for $50 \mathrm{~min}$ at room temperature (RT). Solidified PA hydrogel was then removed and spoiled in deionized water overnight. After adding $0.2 \mathrm{mg} / \mathrm{ml}$ sulfo-SANPAH solution (cross-linking agent) in an adequate volume, the mixture was irradiated with ultra-violet light for $5 \mathrm{~min}$. The planar PA hydrogel was cut into rectangular strips to estimate its Young's modulus using a selfweighing assay, which yielded $E=6.1$ and $46.7 \mathrm{kPa}$ at the two bis-acrylamide concentrations, respectively [29]. Finally, the PA hydrogel was prepared in the form of discs (20 mm in diameter and $0.1 \mathrm{~mm}$ in thickness) with the following three topographies: groove (ridge width/ditch width $=5 / 15 \mu \mathrm{m}$ ), hexagonal (ridge width/ side-length $=5 / 15 \mu \mathrm{m}$ ), and square pillar (side-length/inter-pillar gap size $=10 /$ $10 \mu \mathrm{m}$ ) configurations with the same depths of $5 \mu \mathrm{m}$; a planar PA hydrogel of the same diameter and thickness was used as the control. Collagen I ( $1 \mathrm{ml}$ of $200 \mu \mathrm{g} / \mathrm{ml}$ ) was cross-linked securely onto the PA hydrogel surface prior to seeding the cells $[29,30]$.

\subsection{Cells and reagents}

R1 mESCs (a gift from Dr. Yeguang Chen in Tsinghua University) were grown under serum-free conditions co-cultured with mitomycin C-treated MEFs as the feeder cells. The cells were cultured in T-25 flasks or 6-well plastic plates (Tissue culture treated or TC-treated, Corning, USA) that were pre-coated with $0.1 \%$ gelatin. For serum-free culture, mESCs were maintained in H-DMEM medium, supplemented with $15 \%$ knockout serum replacement (KSR), 2 mm L-glutamine, 0.1 mм nonessential amino acids (NEAA), $1 \mathrm{~mm}$ sodium pyruvate, $0.1 \mathrm{~mm}$ beta-mercaptoethanol (2-ME), $1000 \mathrm{U} / \mathrm{ml}$ LIF (all from Invitrogen), $4 \mathrm{ng} / \mathrm{ml}$ bFGF (R\&D, USA), $100 \mathrm{U} / \mathrm{ml}$ penicillin, and $100 \mathrm{mg} / \mathrm{ml}$ streptomycin (Hyclone, USA). To distinguish the feeder-free mESCs from R1 cells cultured on MEF cells, feeder-dependent R1 cells were cultured on a collagen I $(200 \mu \mathrm{g} / \mathrm{ml})$ - coated dish in the presence of LIF. After 1-2 passes under feeder-free conditions, the MEF cells were completely removed, and the expanded R1 cells were stocked in liquid nitrogen or used directly in the functional experiments. The frozen cells were then thawed out and maintained in a humidified, $95 \%$ air $/ 5 \% \mathrm{CO}_{2}$, $37{ }^{\circ} \mathrm{C}$ incubator by exchanging the medium every day. When feeder-free R1 mESCs were grown to $85 \%$ confluence, the cells were rinsed in $\mathrm{Ca}^{2+}$ - and $\mathrm{Mg}^{2+}$-free PBS and then detached using TrypLE ${ }^{\mathrm{TM}}$ Select (Invitrogen, USA) for 1-2 min. Collected R1 cells were seeded onto the PA or PS substrate of conventional petri dishes at a density of 5000 cells $/ \mathrm{cm}^{2}$ for up to $72 \mathrm{~h}$. In some cases, CF- 1 MEFs purchased from ATCC (USA) were pre-cultured on the polystyrene substrate until they reached $70-85 \%$ confluence in order to form the monolayer of feeder cells before adding the collected mESCs or mESC culture medium. When culturing feeder-free R1 mESCs on a PA gel, MEF conditioned medium (CM) was used [31].

Alexa Fluor $^{\circledR} 488$-conjugated rabbit-anti-mouse anti-Oct-4 monoclonal antibodies (mAbs) and Alexa Fluor ${ }^{\circledR}$ 647-conjugated rabbit-anti-mouse anti-Nanog mAbs were purchased from Cell Signaling Technology (USA). Hoechst 33342 from Enzo (USA) was used to stain the nuclei of the cells.

\subsection{Immunological staining and confocal microscopy}

The expression of the typical stemness biomarkers Oct-4 and Nanog was visualized via confocal microscopy. mESCs cultured on the substrate were rinsed in PBS at $\mathrm{pH} 7.2$, fixed for $20 \mathrm{~min}$ in $4 \%$ paraformaldehyde, and permeabilized with $0.4 \%$ Triton 100 -X for 15 min. The collected cells were stained with Alexa Fluor ${ }^{\circledR} 488$ conjugated anti-Oct- 4 mAbs and Alexa Fluor ${ }^{\circledR}$ 647-conjugated anti-Nanog mAbs diluted in $1 \%$ bovine serum albumin/PBS (to block nonspecific epitopes) at $4{ }^{\circ} \mathrm{C}$ overnight. Then, the collected samples were incubated with Hoechst 33342 for 10 min at RT, washed 3-5 times with PBS, and stored at $4{ }^{\circ} \mathrm{C}$ for examination with confocal laser scanning microscopy (Zeiss L710, Germany).

\subsection{Morphology, proliferation, and stemness}

The morphology of mESCs was determined using optical images of their colonies on the planar or topographical substrates. For each topographical substrate, the number of mESC colonies was counted, and the projected area, aspect ratio between long and short axes, and circularity (defined as $4 \pi \times$ area/perimeter ${ }^{2}$ ) of the colonies were measured for quantitative comparison. For each colony, the relative fluorescence intensities (RFI) of the two stemness biomarkers (Oct-4 and Nanog) were estimated using Image J software, where in Oct- 4 staining was used to help identify the contours of the colony. Five of a total of 18-28 colonies in each case were selected randomly for the aforementioned estimations.

\subsection{Statistical analysis}

Each experiment was performed in triplicate unless stated otherwise. The Student's two-tailed $t$-test was used to determine the statistical significance of differences between any two cases for each estimated morphological or fluorescent parameter, on the planar or topographical substrate, for the morphology, proliferation, and stemness of the cells.

\section{Results}

\section{1. mESCs on planar substrates}

To mimic the pluripotent responses of mESCs under the twodimensional (2D) niche, mESCs were first placed on a planar PA 
substrate at the elasticities $E=46.7 \mathrm{kPa}$ (stiff) and $6.1 \mathrm{kPa}$ (soft) in planar patterns as well as on PS substrates used as controls. Notably, mESCs possessed clear morphologies and formed welldefined colonies after $72 \mathrm{~h}$ regardless of whether feeder cells were present (Fig. $1 a$ ) or absent (Fig. 1b) on the PS substrate; this suggests that $\mathrm{mESCs}$ are able to grow even when they are deprived of feeder cells when LIF and Collagen I exist. This observation is meaningful for the study of stemness maintenance and in regenerative medicine. In the absence of feeder cells, mESCs are able to form colonies on stiff (Fig. 1c) or soft (Fig. 1d) PA substrates with slightly less dense, smaller-sized aggregates than those in Fig. $1 b$. We also quantified the morphology of mESCs on different substrates. As exemplified in Fig. 1e, the projected area depicts slightly higher values for cells on PS substrates than those on PA substrates, but no significant differences were found between the two conditions ( $P>0.12$ for all values). Furthermore, the colonies are more evenly sized on the soft PA substrate $\left(131.5 \pm 20.7 \mu \mathrm{m}^{2}\right)$ than those on the stiff $\left(136.3 \pm 42.9 \mu \mathrm{m}^{2}\right)$ PA substrate because the former yields a smaller deviation in the colony size (Fig. 1e). This observation was confirmed by estimating the morphology and geometry of the mESC colonies. The aspect ratios, circularities and colony numbers revealed similar values in all four cases (Fig. $1 g-h$; $P>0.05$ for all values). Meanwhile, mESCs effectively adhered to the substrate in each case, which is a prerequisite for maintaining their stemness. These brief results, obtained from cells cultured on planar substrates, are consistent with the results of other studies, which reported that substrate stiffness regulates mESC colonization $[19,32,33]$.

\subsection{Stiffness on mESC stemness}

We further tested the impact of the substrate stiffness on mESC stemness retention in the absence of feeder cells at $72 \mathrm{~h}$ (Fig. 2). The results of the Oct- 4 and Nanog staining indicated that colony spread varied from sparse for the PS substrate to intermediate for the stiff PA substrate to condensed for the soft PA substrate (1st and 2nd columns of the images); these results are consistent with the projected area data ( $c f$. Fig. 1e). A similar trend of sparse to condensed spreading was also observed in images of stained nuclei (3rd column) and of DIC visualization (5th column). Oct- 4 and
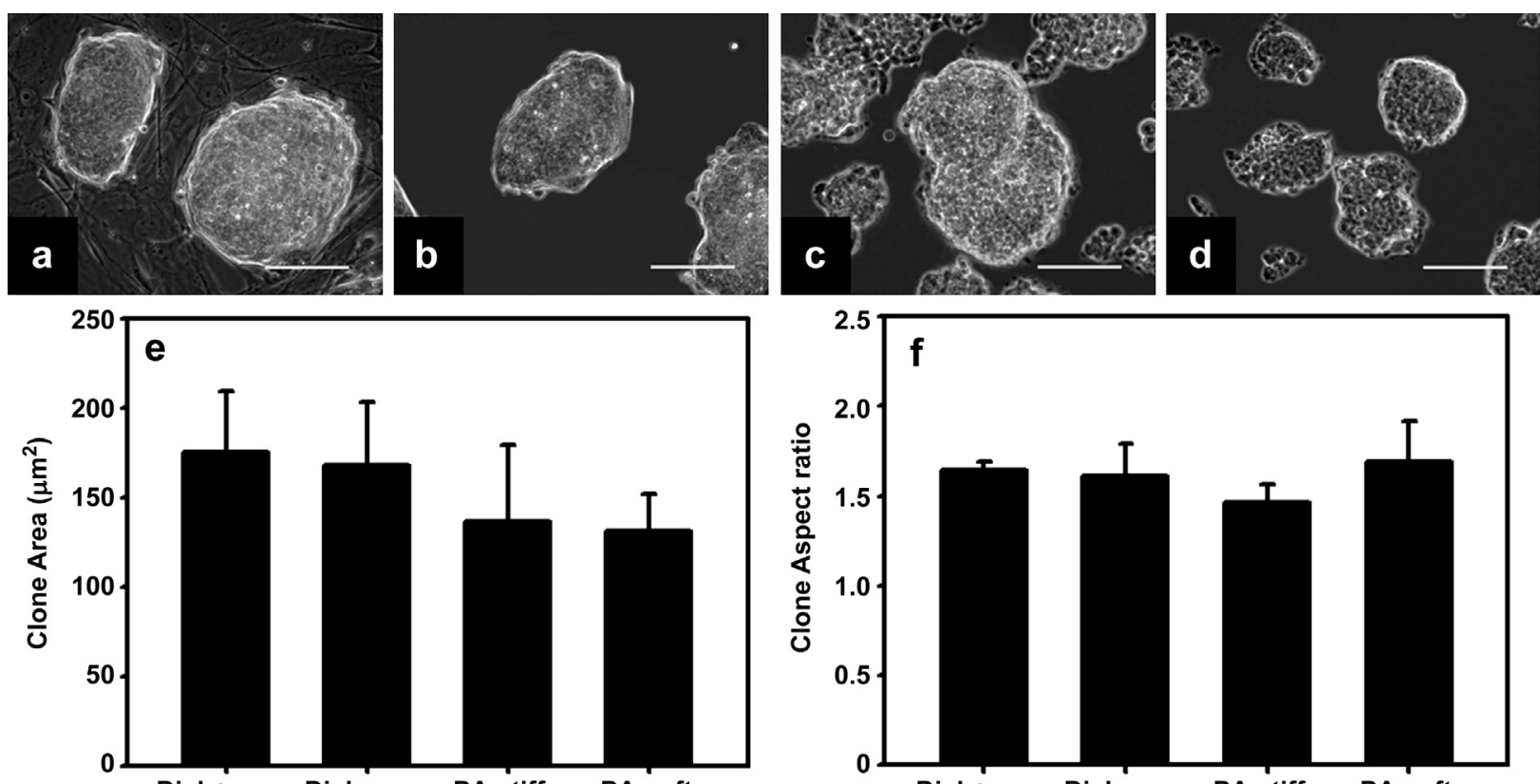

Dish+ Dish- PA stiff- PA soft-

feeder cell feeder cell feeder cell feeder cell
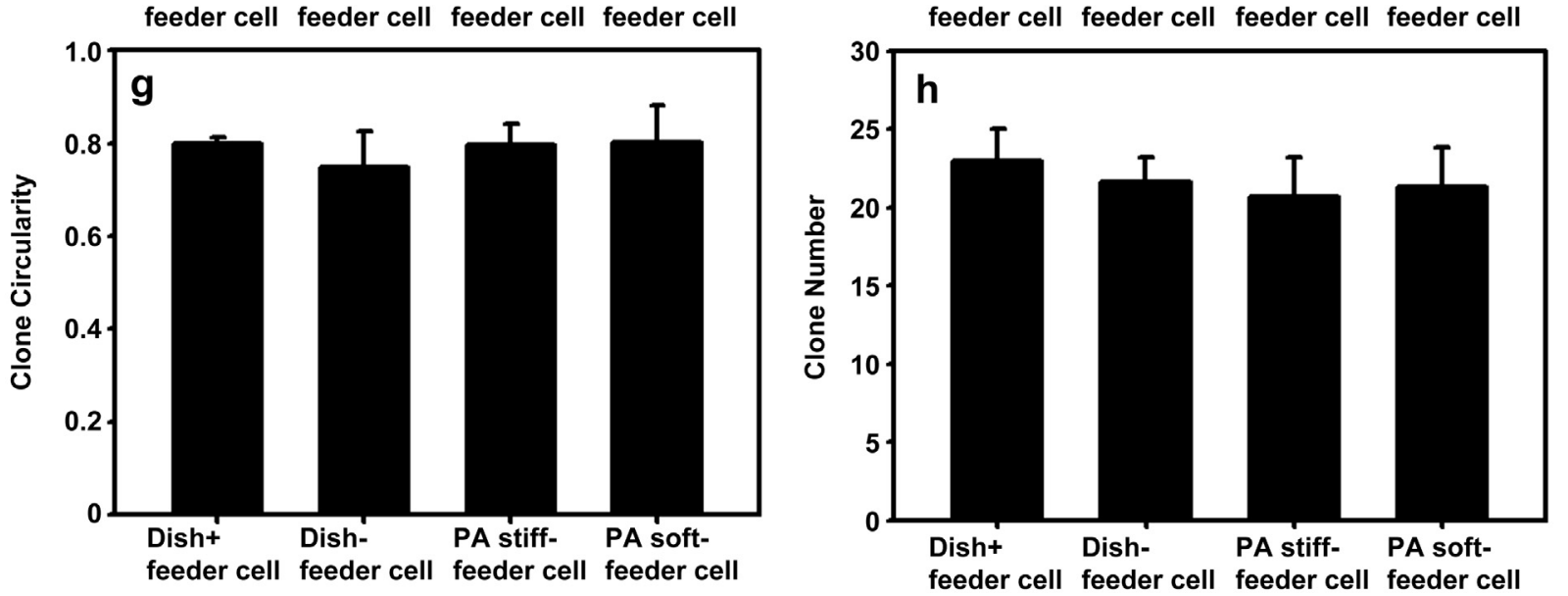

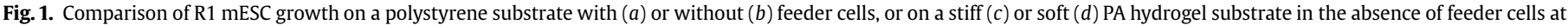

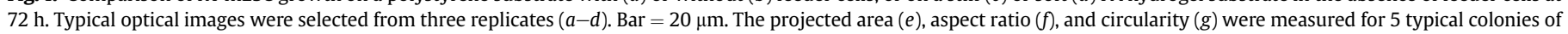
a total of $18-25$ colonies $(h)$ in each replicate and presented as the mean \pm standard deviation (SD) from triplicate runs. 

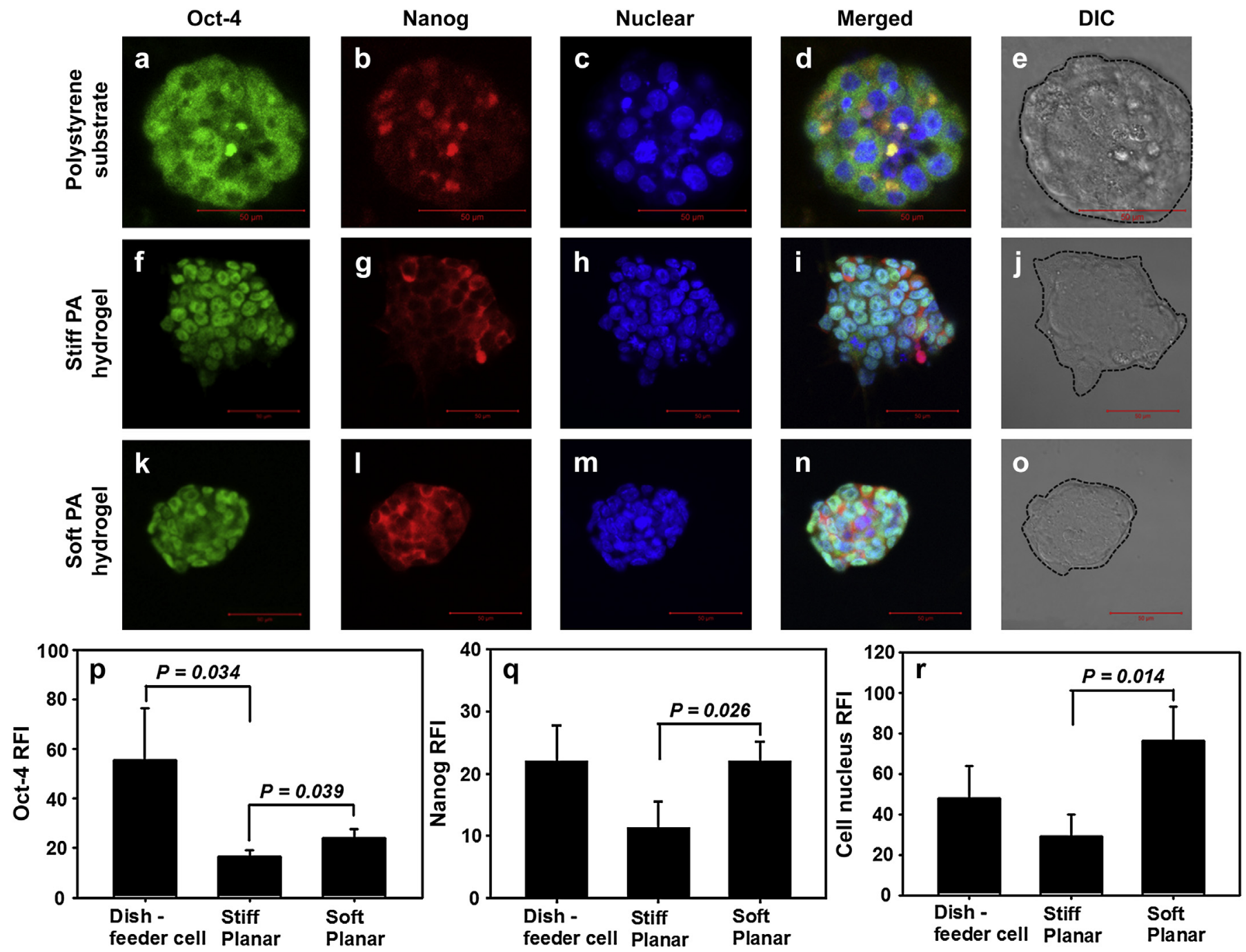

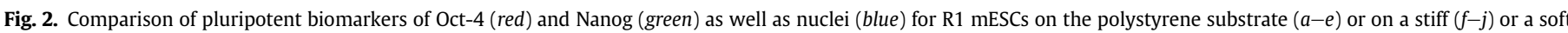

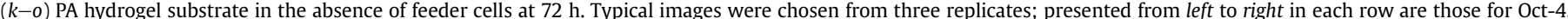

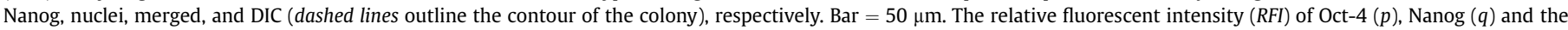

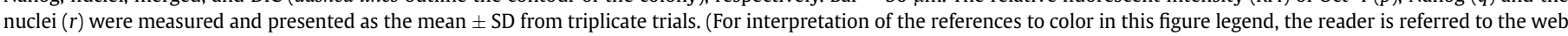
version of this article.)

Nanog were less co-localized in the nuclei of cells cultured on the PS substrate than for the cells on stiff or soft PA substrates, even though the biomarkers each co-localized well in each case (4th column). On the other hand, these results also indicate that the mESCs retained their stemness because two typical biomarkers were well expressed in the mESCs cultured on all three substrates (1st and 2nd columns); the cell colonies had smooth boundaries, clear nuclei, and co-localized biomarkers (3rd and 4th columns). The Oct-4 and Nanog expression was higher on the soft PA substrate (Fig. $2 k-l$ ) than on the stiff PA substrate (Fig. $2 f-g$ ), which suggests that, as expected, the mESCs retained pluripotency on the soft substrate [19]. These expression of Oct-4 and Nanog seemed relatively high in cells cultured on the PS substrate (Fig. 2a-b), implying that feeder cells or other characteristics of the surface coating (e.g., TC-treated petri dish vs. Col-I-coated PA hydrogel) might play a role in preserving stemness because the stiffness of the polystyrene substrate petri dish is much higher ( $\sim 1 \mathrm{GPa})$ than the PA hydrogel substrates.

The relationship between the substrate stiffness and mESC stemness was further quantified by comparing the relative fluorescent intensity (RFI) frequently tested in all three cases. No differences in Oct- 4 and Nanog expression were found between cells cultured on the PS and PA substrates except in one case, in which Oct-4 expression was significantly higher than in cells cultured on the stiff PA substrate $(55.4 \pm 21.1$ and $16.5 \pm 2.6$, respectively, $P=0.034$ ) (Fig. $2 p$ ). This result implies that the capacity to preserve mESC stemness is similar for cells cultured on both PS and PA substrates. For the two PA substrates, however, cells showed lower Oct-4 (16.5 \pm 2.6 and $24.1 \pm 3.5, P=0.039)$ (Fig. $2 p)$ and $\operatorname{Nanog}(11.3 \pm 4.3$ and $21.9 \pm 3.2, P=0.026)$ (Fig. $2 q)$ expression when cultured on stiff hydrogel than cells cultured on soft hydrogel, which suggests that the soft hydrogel was more favorable for maintaining stemness. These results indicate that the stemness of mESCs is well preserved when mESCs are grown on PA gels. Additionally, the results indicate that higher RFI values were found in the nuclei of mESCs cultured on the soft PA substrate than in those cultured on the stiff PA gel (Fig. 2r). These results suggest that mESC nuclei tend to be closely condensed with high viability on soft substrates, which promotes stemness maintenance. 


\section{3. mESCs on topographical substrates}

While surface chemistry and substrate stiffness can modulate the stemness of mESCs, substrate topography is also crucial in stem cell function [29]. To mimic the pluripotent responses of mESCs in a 3D niche, the impact of substrate topography on both stiff and soft PA substrates was systematically tested using three defined groove, hexagonal, and square pillar configurations at $72 \mathrm{~h} \mathrm{mESCs}$ had clear morphologies, adhered stably, and formed well-defined colonies in the absence of feeder cells (Fig. $3 a-f$ ), which suggests that mESCs can grow effectively on the topographical PA substrate. Again, mESCs colonies seemed evenly sized on the stiff (Fig. $3 a-c$ ) or soft substrates (Fig. $3 d-f$ ) or substrates in between; these results match the observations made on planar PA substrates ( $c f$. Fig. $1 c-d)$.

The morphology of mESC colonies was further quantified based on topographical substrates. As exemplified in Fig. $3 g$, similar projected area values were calculated for the three topographical configurations on both stiff $\left(187.0-198.0 \mu \mathrm{m}^{2} ; P>0.46\right.$ for all values) and soft (150.2-178.7 $\mu \mathrm{m}^{2} ; P>0.53$ for all values) PA substrates. The value of the projected area was slightly lower in planar configurations in both stiff $\left(136.3 \mu \mathrm{m}^{2}\right)$ and soft $\left(131.5 \mu \mathrm{m}^{2}\right)$ substrates, which suggests that $\mathrm{mESC}$ colonies require a large amount of space to fit the substrate topography. However, there were no significant differences between the topographical and planar substrates of the same stiffness ( $P>0.08$ for all values). To further test whether there was a combined effect from the substrate stiffness and topography, the data from each stiff (or soft) topography were compared with data from three soft (or stiff) topographies. Again, no significant differences were found between each pair of crossed comparisons (for all values, $P>0.05$ ), which indicates that either stiffness or topography most likely plays an independent role in colony formation on 3D substrates. The projected area values were significantly higher for stiff, hexagonal $\left(198.0 \pm 15.1 \mu \mathrm{m}^{2} ; P=0.011\right)$ and square pillar $\left(187.0 \pm 18.1 \mu \mathrm{m}^{2}\right.$;


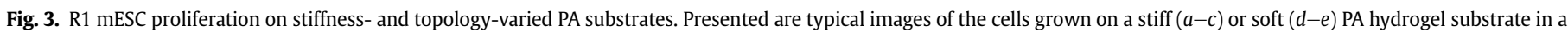

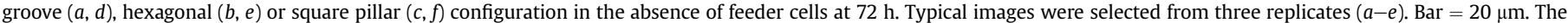

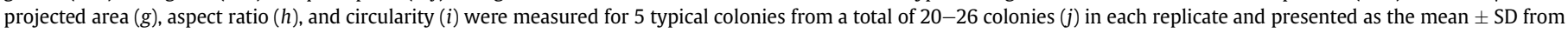
triplicate trials. 
$P=0.025)$ substrates than that for the soft planar $\left(131.5 \pm 20.7 \mu \mathrm{m}^{2}\right)$ substrate, which suggests that stiffness and topography have a combined effect on 3D and 2D maintenance.

Similar comparisons were performed for the colony aspect ratio, circularity, and colony number. No significant differences were found in the aspect ratio among the three topographical configurations on either stiff $(1.36-1.57 ; P>0.07$ for all values) or soft (1.43-1.47; $P>0.17$ for all values) substrates, between topographical and planar substrates of the same stiffness $(P>0.07$ for all values), or in crossed comparisons at a distinct stiffness $(P>0.07$ for all values) (Fig. $3 h$ ). Similar readouts were obtained in the comparisons of the colony circularity, except that a slightly higher aspect ratio was observed in the hexagonal configuration $(1.57 \pm 0.03 ; P=0.010)$ than in the square pillar $(1.36 \pm 0.15)$, which were both on stiff substrates. Combined with the relatively low aspect ratio $(=0.70)$, this difference indicated that colonies were elongated on the stiff, hexagonal substrate (Fig. $3 i$ ). By contrast, no significant differences in the colony number were observed among the three topographical configurations on either the stiff (22.024.3; $P>0.29$ for all values) or soft (22.7-24.3; $P>0.38$ for all values) substrates, between topographical and planar substrates at the same stiffness $(P>0.12$ for all values), or in crossed comparisons at a distinct stiffness $(P>0.29$ for all values) (Fig. $3 j)$. Taken together, these simple analyses suggest that mESCs grow well on topographical substrates and form colonies with projected area, circularity, and colony number values comparable to those grown on planar substrates.

\subsection{Topography on mESC stemness}

Next, we further tested the impact of substrate topography on retaining mESC stemness in the absence of feeder cells at $72 \mathrm{~h}$. Similar to the cells on the planar PA substrate, two typical biomarkers of Oct-4 (1st row) and Nanog (2nd row) were well expressed and co-localized with each other (4th row) as well as with their nuclei (3rd row) on the PA substrate in groove, hexagonal, or square pillar configuration (Fig. 4). Specifically, the Oct-4 and Nanog biomarkers tended to be uniformly distributed on the groove (1st and 4th columns) or hexagonal (2nd and 5th columns) substrate. By contrast, they seemed to form clusters on the square pillar substrate (arrows in 3rd and 6th columns) when the cells were likely to stick to the ridges, suggesting that the expression of pluripotent biomarkers is sensitive to the pillar configuration. The cell nuclei may also mainly settle down into the pits for the groove
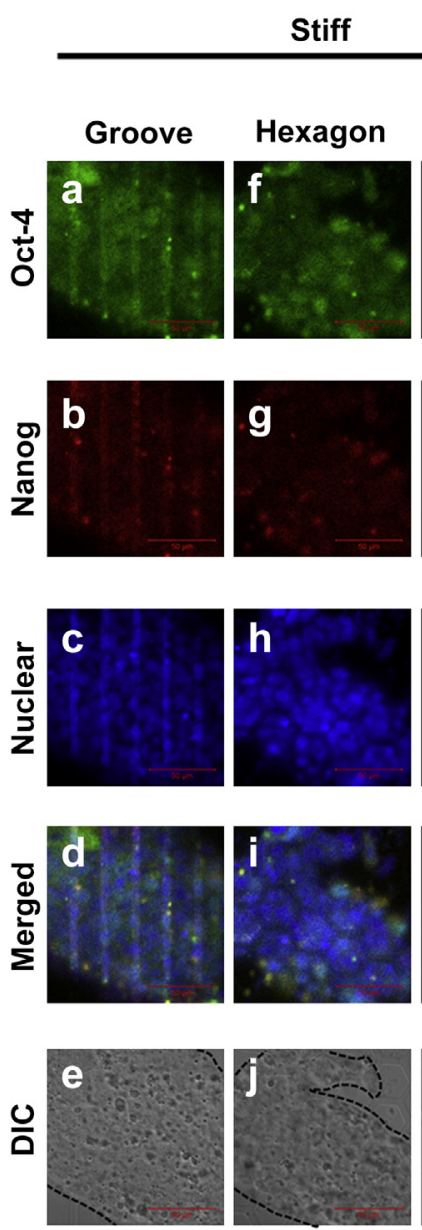
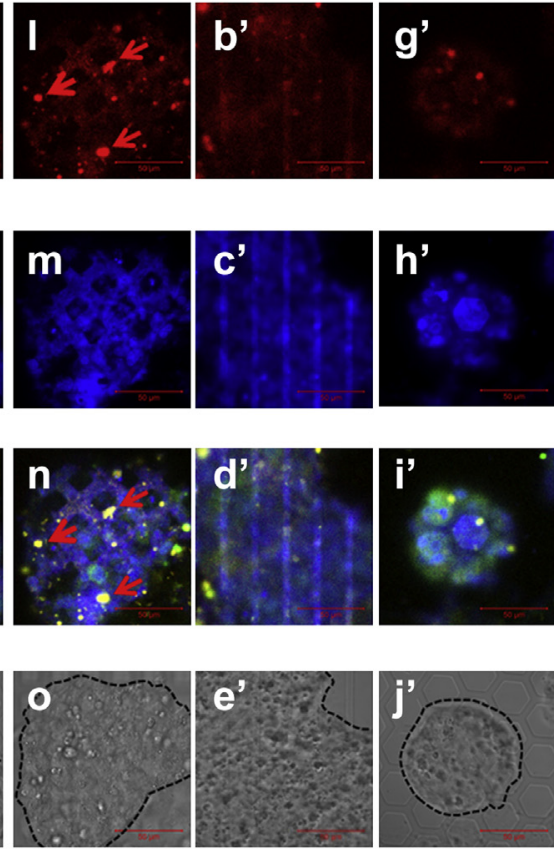
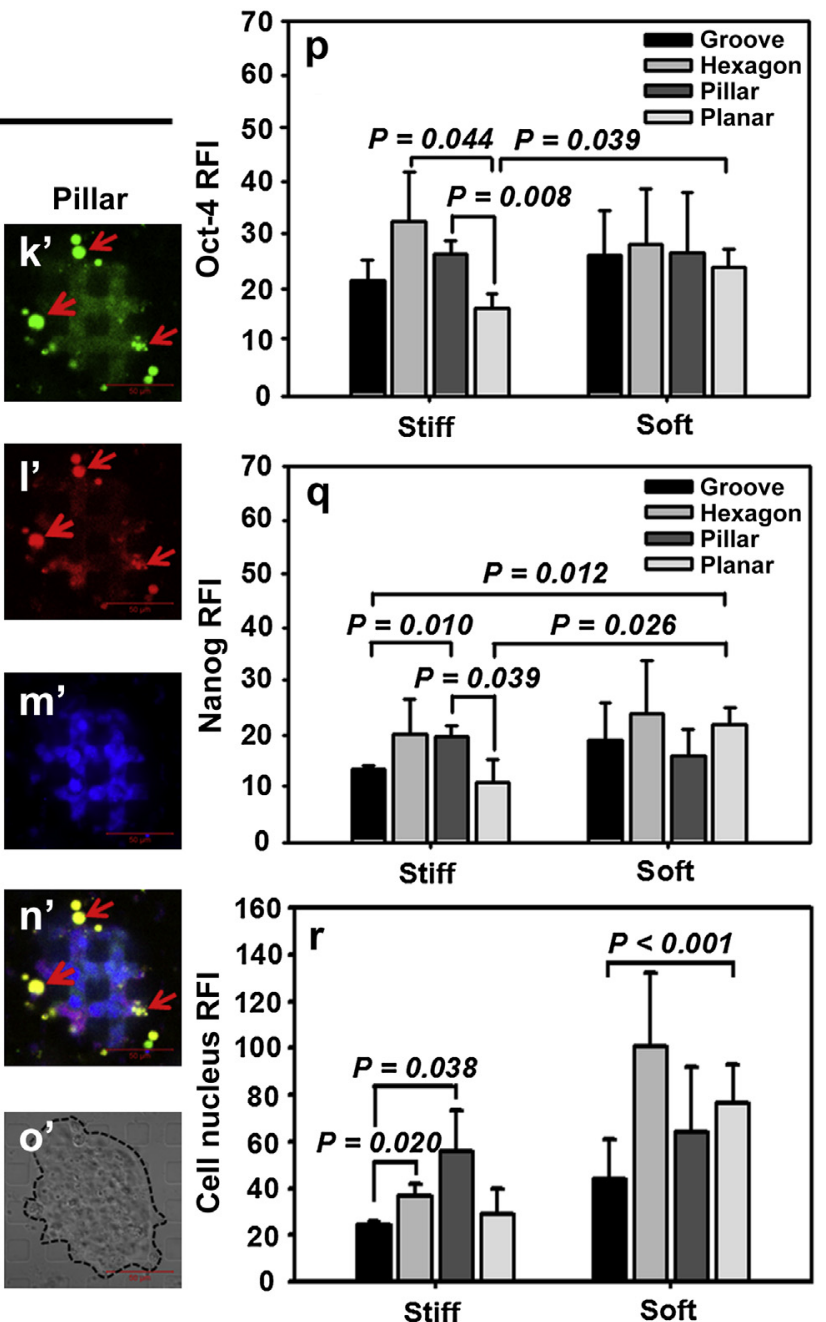

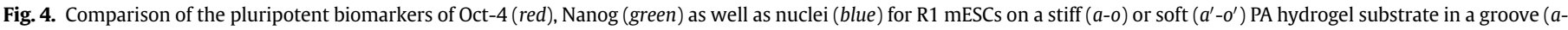

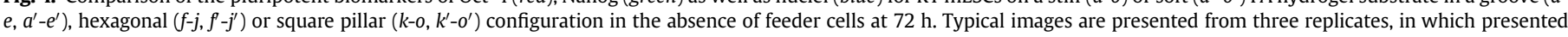

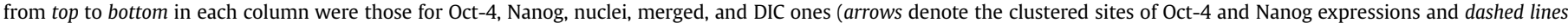

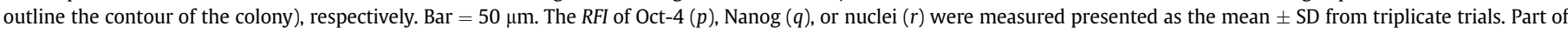
data in Fig. 2 were re-plotted here for comparison. (For interpretation of the references to color in this figure legend, the reader is referred to the web version of this article.) 
or hexagonal configuration, whereas they likely stick to the ridge in square pillar configuration, especially for those on the soft PA substrate (3rd row). Although the observation of the distinct locations of the nuclei also depends on the geometry (size) of the topographical substrates used [29], these findings still indicate that mESC spreading may depend on the topography. In fact, mESCs seemed to form less condense, relatively flatted colonies (Fig. $4 e-o$ and $\left.4 e^{\prime}-0^{\prime}\right)$ in the groove and square pillar configurations compared to those on the planar PA substrate ( $c f$. Fig. $2 e-0$ ). Similar sparse spreading was also observed from the images of stained nuclei, indicating the guidance of substrate topography for the nucleus distribution (3rd row in Fig. 4). These results indicate that mESCs preserve their stemness on topographical substrates.

To further quantify the impact of substrate topography on stemness maintenance, the RFI values were estimated and then compared for the six combinations of three topographies and two elasticities. On soft PA substrate, no significant differences in the Oct-4 (Fig. 4p) and Nanog (Fig. 4q) expressions were found among the three distinct topographies (all the values, $P>0.28$ ) and between each of the topographical and planar substrates (all the values, $P>0.16$ ), suggesting that the topography effect is insensitive to maintaining mESC stemness on soft hydrogel. On a stiff PA substrate, similar Oct-4 (Fig. $4 p$ ) and Nanog (Fig. 4q) expression levels were also visualized among three distinct topographies $(P>0.13$ for all the values) except for one case in which the Nanog expression was higher on the square pillar substrate than that on the groove substrate $(19.7 \pm 2.2$, and $13.7 \pm 0.6, P=0.010)$ (Fig. $4 q)$ indicating that the three topographies have different roles in modulating stemness preservation on a stiff substrate. Interestingly, Oct-4 expression was higher in the hexagonal $(32.6 \pm 9.2, P=0.044)$ or pillar $(26.6 \pm 2.5, P=0.008)$ configuration than for the planar one $(16.5 \pm 2.6)$ (Fig. $4 p)$, and Nanog expression was higher in the pillar $(19.7 \pm 2.2, P=0.039)$ configuration than for the planar one $(11.3 \pm 4.3)$ (Fig. $4 q)$, indicating that at least hexagonal or pillar topography plays a role in fostering stemness maintenance. Groove topography seemed to have little effect on altering the capacity of stemness maintenance because the Oct- 4 and Nanog expression levels were comparable between the groove and planar configurations on the stiff PA substrate (Fig. $4 p-q$ ). While the soft planar substrate is favorable for stemness maintenance of Oct- 4 and Nanog expression (Fig. $4 p-q$ and Fig. $2 p-q$ ), the soft planar substrate may play a more important role than the stiff groove substrate because Nanog expression was higher for the former $(21.9 \pm 3.2, P=0.012)$ than that for the latter $(13.7 \pm 0.6)$. These results suggest that, while the topography effect is less critical than the stiffness for mESC stemness on a soft hydrogel, it is relatively favorable for stemness maintenance on stiff, hexagonal and pillar PA substrates. Additionally, the $R F I$ value on the stiff substrate was higher in the hexagonal $(P=0.020)$ and pillar $(P=0.038)$ configuration than in the groove configuration, whereas the RFI value was significantly higher $(P<0.020)$ on the planar substrate than on the groove substrate for the cells on the soft substrate (Fig. $4 r$ ), which, combined with the observation of the nuclei localization (3rd row of images in Fig. 4), elucidates the 3D structure of the colonies formed.

\section{5. $3 D$ feature of $m E S C s$ on a hexagonal substrate}

We further tested the 3D characteristics of mESCs on a topographical substrate using sliced images. A typical colony on a stiff, hexagonal substrate tended to form a 3D structure with a height of $\sim 30 \mu \mathrm{m}$ (Fig. 5a). From sequential, sliced images, a spheroid-like configuration of the colony was observed from the top (1st and 2nd rows), which is different from the flatted one on the planar substrate ( $c f$. Fig. $3 b$ ). The hexagonal pit of the substrate began to appear with the adhered cells at a height of $\sim 24 \mu \mathrm{m}$ from the top and reached a clear contour at the bottom plane of the substrate with invisible cells (3rd row). At the vicinity of the substrate bottom, mESCs were able to cross over the adjacent pits and surround them. Moreover, the cells sitting on the right top of a pit couldprotrude into and fill in the entire pit. The height of the protruding part was estimated to be $\sim 5-6 \mu \mathrm{m}$ (thickness between 1st to 4th panels in the 3rd row), which matched the designed depth of the pit. This observation was also confirmed by the cross-sectioned images along two perpendicular directions, wherein the in-pit multiple nuclei were evidently visualized (Fig. 5b). A 3D reconstructed image displayed the detailed configuration of the hexagonal ridge and pit with the surrounding cells (Fig. 5c). Similarly, the colonies on the groove substrate retained a 3D-like structure with the majority of cell nuclei settling down into the groove pit (cf. Fig. $3 a$ and $d$ and 3rd row in Fig 4), whereas those on the square pillar substrate tended to form a relatively flattened, 2D-like structure with most of the nuclei sticking onto the ridge of pillars ( $c f$. Fig. $3 c$ and $f$ and 3rd row in Fig 4). Only several slices could be obtained for these flattened images (data not shown) on the pillar substrate and we were unable to perform 3D reconstruction of the square pillar substrate images.

\subsection{Early phase of mESC growth on topological substrates}

Finally, we tested the early-phase responses of the morphology and proliferation of mESC colonies on topological substrates. At $24 \mathrm{~h}, \mathrm{mESCs}$ possessed clear morphology, adhered stably, and formed well-defined colonies with smaller sizes (Fig. $6 a-f$ ), suggesting that mESCs are able to grow well at the early phase on a topographical PA substrate. Again, no significant differences in the projected area (Fig. 6g), aspect ratio (Fig. 6h), circularity (Fig. 6i), or colony number (Fig. $6 j$ ) were found among the three topographical configurations on either stiff or soft substrates $(P>0.10$ for all values), between topographical and planar substrates at the same stiffness $(P>0.26$ for all values), or in crossed comparisons at a distinct stiffness ( $P \geq 0.05$ for all values). These results indicate that substrate stiffness and topography have little impact on mESC colonization and colony morphology in the early phase.

We further compared the proliferation and morphology of mESC colonies data between the paired cases at 24 and $72 \mathrm{~h}$. The projected area at $72 \mathrm{~h}$ was 4.5-, 7.0-, 6.6-, and 6.8-fold enhanced on the stiff substrate and 4.5-, 5.7-, 5.9-, and 5.3-fold increased on the soft substrate, in the planar, groove, hexagonal, and square pillar configurations, respectively ( $c f$. Figs. 1, 3 and 6), supporting that mESCs are well colonized on stiffness-varied, topographical substrates. The proliferation rates were slightly higher on the stiff substrate than that on the soft substrate in the three typical topographies, suggesting that the stiff topography favors mESC colonization. By contrast, comparisons of the aspect ratio and circularity yielded no differences for each paired case; the colonies most likely retained their morphologies at $72 \mathrm{~h}$. However, the aspect ratio was higher $(1.57 \pm 0.03 ; P=0.006)$ but the circularity was lower $(0.70 \pm 0.05$; $P=0.009$ ) at $72 \mathrm{~h}$ than at $24 \mathrm{~h}$ on a stiff, hexagonal substrate $(1.35 \pm 0.07$ for aspect ratio and $0.89 \pm 0.03$ for circularity), suggesting that the mESC colonies tend to be further developed with time. Again, no significant difference in the colony number was observed in each paired case $(P>0.18$ for all values), indicating that the given number of colonies was formed at $24 \mathrm{~h}$ no matter how small the colonies were. Taken together, these analyses support that mESCs grow well on topographical substrates in the early phase, forming stable, small colonies.

\section{Discussion}

While the stem cell niche is well known to regulate stem cell stemness and differentiation in vivo [34,35], embryonic stem cells 

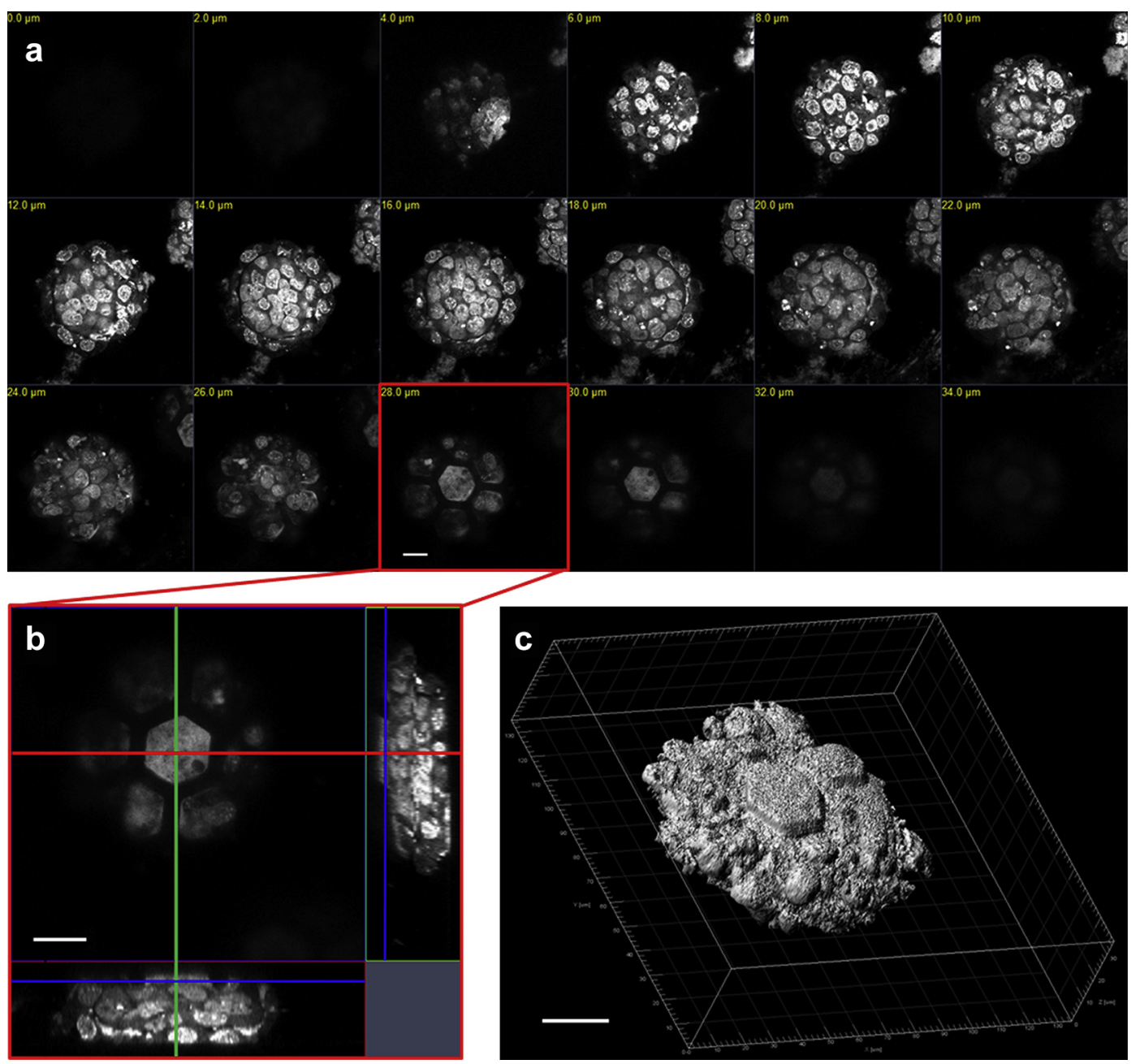

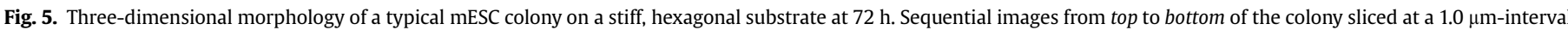

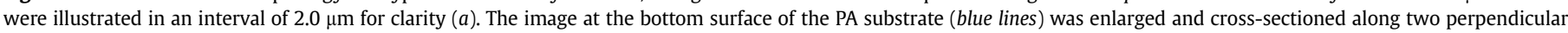

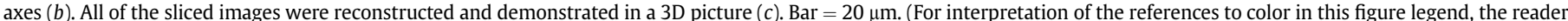
is referred to the web version of this article.)

generally undergo spontaneous differentiation to specific germ layers or cell types in vitro. A reasonable explanation for the failure of stemness maintenance is that ESCs do not have an in vitro microenvironment that matches the optimally developed in vivo scenario. Matrix stiffness or topography of the niche plays an important role in cell behaviors [36], particular in cell locomotion [37], proliferation [38], self-renewal [28,39], and differentiation $[32,40]$. Recently, growing evidence confirms that there is a relationship between cell behaviors and matrix stiffness or topography maintaining the stemness (or differentiation) of mESCs. However, the biological responses to the 3D microenvironments that couple the stiffness and topography of the ECM in embryonic stem cells have not previously been evaluated.

In the present study, we sought to determine the independent or combined effect of stiffness and/or topography of PA substrates in maintaining the stemness of mESCs. Using typical combinations of two elasticities and three topographies, we proposed distinct roles for the two regulating factors in MESC self-renewal and fate. The novelty of the current work lies in that mESCs maintain their stemness on the PA hydrogel substrate in a feeder-free manner, in which stiffness is the pre-dominant regulator and topography is a secondary regulator. While a soft PA hydrogel is favorable for stemness maintenance, a groove or hexagonal topography plays a complementary role in mESC self-renewal, especially for a stiff PA substrate. Moreover, a hexagonal PA substrate helps mESCs maintain their 3D structure and stemness. To the best of our knowledge, this is the first study to unravel the respective contributions of the two factors in preserving mESC stemness, shedding light on how to replicate the in vivo 3D niche using an in vitro approach.

This differential effect is biologically relevant because substrate stiffness and topography are often coupled in the in vivo 3D stem cell niche. On one hand, substrate stiffness alone seems insufficient for regulating mESC morphology and proliferation because no significant differences were found in the cell perimeter and density on a PDMS substrate for a range of $41-2700 \mathrm{kPa}$ [32], which is consistent with our data of the colony area and number on the planar PA substrate (Fig. $1 e$ and $h$ ). These are not inconsistent with the previous report that mESC proliferation is enhanced from $41 \mathrm{kPa}$ to $2.3 \mathrm{MPa}$ on a PDMS substrate [32] because stiffness usually works in an elasticity- and material-specific manner, as exemplified in the indifferent human mesenchymal stem cells (MSC) proliferation between stiff and soft gelatin hydroxyphenylpropionic acid hydrogels [41]. On the other hand, substrate stiffness tends to regulate mESC stemness, which was observed via the high expression levels of stemness biomarkers on the soft PA substrate in the current work (Fig. 2) as well as in the current 

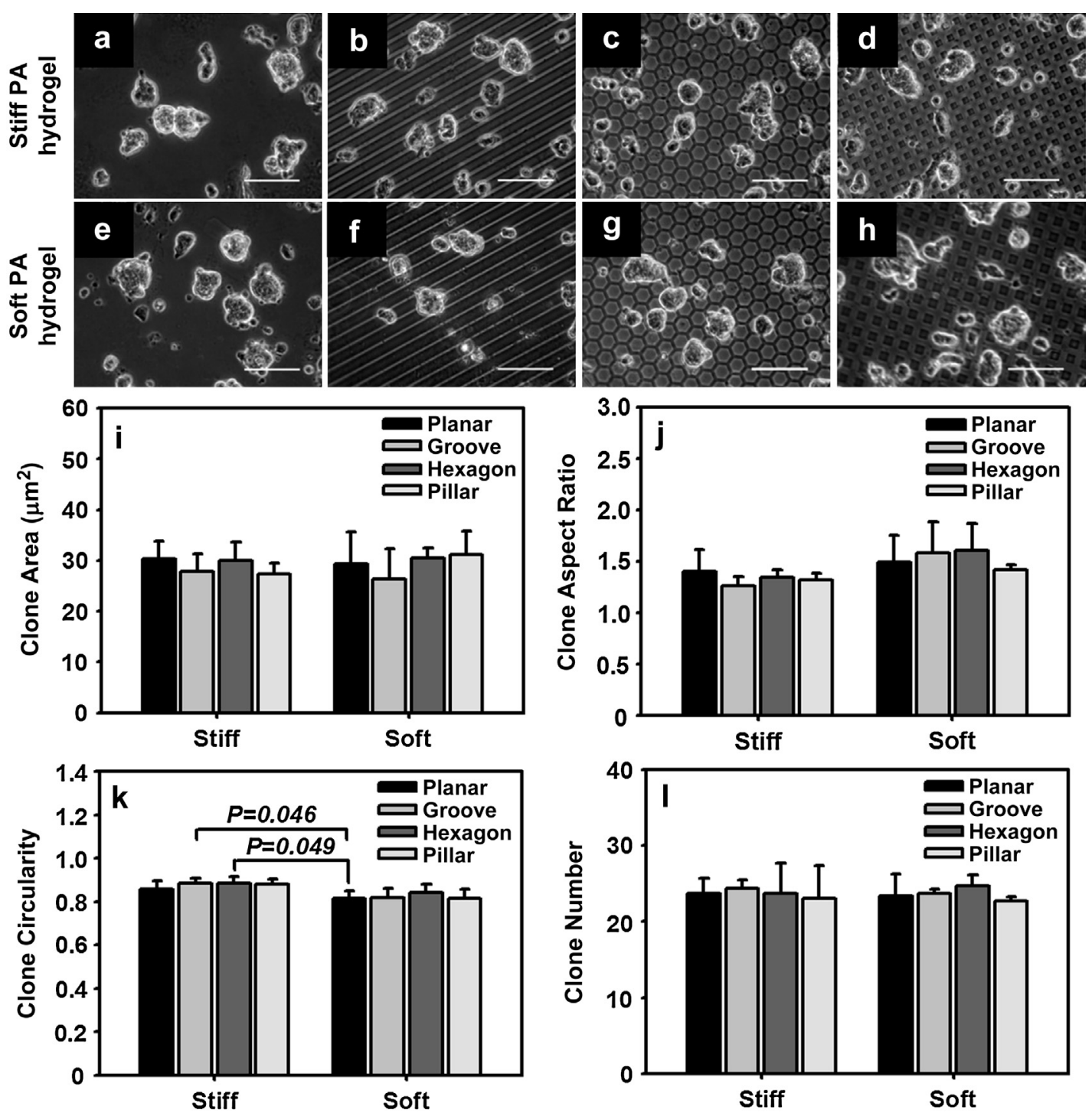

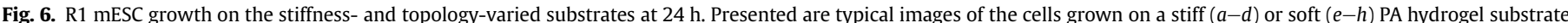

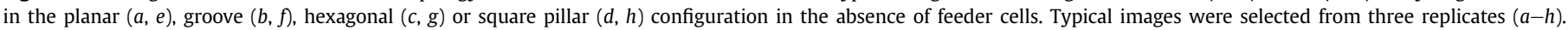

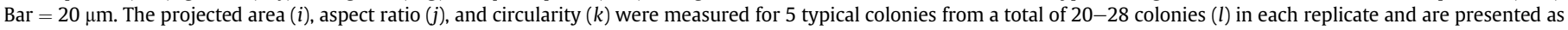
the mean \pm SD from triplicate trials.

literature with a relatively low elasticity of $\sim 0.6-8 \mathrm{kPa}$ [19], supporting that a soft substrate is preferential for preserving $\mathrm{mESC}$ stemness. To date, however, little is known about how substrate stiffness modulates mESC stemness and the details of the mechanotransdution pathways are, which is in contrast with the growing evidence of how stiffness regulates their differentiation [29,4244]. Furthermore, substrate topography is sufficiently sensitive for manipulating stem cell spreading and morphology. Combined with the effect of substrate stiffness, mESC colonies tend to spread further on a stiff, hexagonal or pillar PA substrate than on a soft, planar substrate (Fig. $3 g$ ) even though the directed alignment of grooved topography, used for the guidance of individualized stem or precursor cells [29,45-48], is not observed for mESC colonies (Figs. 3 and 6). Morphological changes in colony circularity are also observed independently (Fig. 3i) or in combination with stiffness (Fig. 6i), and the 3D structure of the colony is most likely formed from cells filling the pits on a groove or hexagonal PA substrate (Fig. 5). More importantly, the topography is a key factor regulating stemness maintenance. While the softness of the PA substrate may be sufficient for preserving the stemness in the groove, hexagonal, pillar, and planar configurations, substrate topography significantly regulates the expression of Oct-4 and Nanog in the four configurations on a stiff PA substrate. This regulation is both independent and in combination with the stiffness (Fig. $3 p-q$ ). Taken together, our data further the understanding of the effect of substrate stiffness and topography on mESC morphological changes and stemness maintenance. The underlying mechanisms in the differences between planar and topographical substrates are not yet clear and require further investigations.

Such biomechanical or biophysical modulation is also meaningful to mESC stemness maintenance. Within the statement "maintaining their stemness in the PA hydrogel substrate" are two key aspects. The first is that the new assay used here can be used maintain mESC stemness so that the mESC cells will not die or differentiate. The second is that this method is at least comparable to biochemically based methods for stemness maintenance. While the deprivation of feeder cells, application of serum-free or conditioned medium, or addition of various growth factors is 
widely used for preserving mESCs stemness, our approach of applying a biomechanically based substrate is free of risk from immunity, easy to implement, and less expensive. Using this approach, one can take the advantages of the state-of-the-art techniques, i.e., biocompatible polymer microfabrication [49,50], self-assembly monolayer [51-53], or microfluidic channels [54,55], to easily construct a hydrogel substrate with various elasticities and topographies in a high-throughput, engineered manner for stemness maintenance and EB formation. This method also allows for the development of customized protocols depending on the types of ESCs that are used, how long stemness is maintained, and where the ESCs are cultured. Such universal modulation would be difficult to achieve with a biochemical approach because the biochemical method involves conditioned medium that varies from one type of feeder cell to another, requires distinct sets of additives or growth factors (i.e., KSR and LIF), and involves labor-intensive, scaled collection in a feeder-free culture.

While the differential impact of various PA hydrogel substrates is well known with respect to cell differentiation regulation, it is also important to understand how to maintain mESC stemness on a topographical substrate. Mechanical clues or forces regulate stem cell functions by altering their shape and cytoskeletal network [56]. In addition to the substrate stiffness defining the fate of ESCs by altering the cell traction force and changing the nuclear translocation of transcription factors, the substrate topography also regulates ESC differentiation by modifying the distribution of focal adhesion complexes and modulating the cell traction [57]. These physical or mechanical signals have differential effects on stem cell functions. The related downstream pathways (integrin, RhoA, and ROCK) need to be clarified in the future work. Thus, a well-defined 3D substratum with appropriate stiffness and topography is crucial to controlling stem cell behaviors in stem cell biology and stem cellbased therapy [58]. Moreover, these findings are also crucial to elucidating the effects of substrate variation on stem cell differentiation because the pluripotency and differentiation of stem cells are two sides of the same coin. For example, rigid fibronectincoated PDMS substrates promote a higher yield of de novo cardiomyocytes from mESCs, and these cardiomyocytes display functional maturity and synchronized beating when they are cocultured with a neonatal cardiomyocyte feeder layer [22]. The combination of stiffness, topography, and geometry of the PA hydrogel reveals the differential regulation of rat MSC morphology, proliferation, and differentiation [29].

While these novel findings are potentially applicable in both stem cell biology and stem cell therapy, there are several remaining issues that should be addressed in the future. One issue is the parameter analysis of the substrate stiffness, topography, or dimension because these parameters in the in vivo 3D niche vary according to site. One example is that dimensional unevenness of the topographical substrate promotes the growth of mESCs presumably due directly to the cells growing in a less confined manner. The spacing and side-length of topographical substrates are known to regulate the stemness and differentiation [29]. The pit depth of the three configurations is also an important factor that is not considered in the current work. Another issue is the combined effect of the stiffness, topography, and dimension. For example, the dimension (depth) and stiffness were found to cooperatively regulate the spreading of human umbilical vein endothelial cells on round pillars made of silica or PDMS [59] or to regulate the spreading of bovine aortic endothelial cells on a grooved PA substrate [60]. Another example is that the main body of evidence supports that rat MSCs have favorable differentiating into neuronal cells on a soft substrate $[29,42,46]$. Thus, care should be taken when the predominance of regulating factors is applied to other types and/or dimensions of the topographical substrates because the importance of each regulating factor depends on the cell type, surface chemistry, mechanical features, and mechanotransductive signaling.

\section{Conclusions}

While the topographically induced fate decision of mESCs is used in vitro to mimic their responses in the physiological 3D niche, their sensitivity and capacity to form cell colonies is dramatically improved via various changes in the stiffness and topography. The mechanism underlying this difference involves their differential ability to alter the morphology and stemness independently. Interestingly, the combined effect of stiffness and topography was also found in the differential modulations of stemness preservation induced by three distinct topographies at a high stiffness. These results imply the differential predominance of mechano-biological responses for mESCs, particularly when they are considered to be a therapeutic cell source for regenerative applications.

\section{Acknowledgments}

This work was supported by National Key Basic Research Foundation of China grant 2011CB710904, National Natural Science Foundation of China grant 31110103918 and 31000421, Strategic Priority Research Program grant XDA01030102, National High Technology Research and Development Program of China grant 2011AA020109.

\section{References}

[1] Suda Y, Suzuki M, Ikawa Y, Aizawa S. Mouse embryonic stem-cells exhibit indefinite proliferative potential. J Cell Physiol 1987;133:197-201.

[2] Johnson KA, Lerner CP, Di Lacio LC, Laird PW, Sharpe AH, Simpson EM. Transgenic mice for the preparation of hygromycin-resistant primary embryonic fibroblast feeder layers for embryonic stem cell selections. Nucleic Acids Res 1995;23:1273-5.

[3] Smith AG. Embryo-derived stem cells: of mice and men. Annu Rev Cell Dev Biol 2001;17:435-62.

[4] Suemori H, Kadodawa Y, Goto K, Araki I, Kondoh H, Nakatsuji N. A mouse embryonic stem-cell line showing pluripotency of differentiation in early embryos and ubiquitous beta-galactosidase expression. Cell Differ Dev 1990;29:181-6.

[5] Bryja V, Bonilla S, Cajánek L, Parish CL, Schwartz CM, Luo Y, et al. An efficient method for the derivation of mouse embryonic stem cells. Stem Cells 2006;24: 844-9.

[6] Bryja V, Bonilla S, Arenas E. Derivation of mouse embryonic stem cells. Nat Protoc 2006;1:2082-7.

[7] Lim JW, Bodnar A. Proteome analysis of conditioned medium from mouse embryonic fibroblast feeder layers which support the growth of human embryonic stem cells. Proteomics 2002;2:1187-203.

[8] Ying QL, Nichols J, Chambers I, Smith A. BMP induction of Id proteins suppresses differentiation and sustains embryonic stem cell self-renewal in collaboration with STAT3. Cell 2003;115:281-92.

[9] Ogawa K, Matsui H, Ohtsuka S, Niwa H. A novel mechanism for regulating clonal propagation of mouse ES cells. Genes Cells 2004;9:471-7.

[10] Ying QL, Wray J, Nichols J, Batlle-Morera L, Doble B, Woodgett J, et al. The ground state of embryonic stem cell self-renewal. Nature 2008;453:519-23.

[11] Williams RL, Hilton DJ, Pease S, Willson TA, Stewart CL, Gearing DP, et al Myeloid leukemia inhibitory factor maintains the developmental potential of embryonic stem cells. Nature 1988;336:684-7.

[12] Smith AG, Heath JK, Donaldson DD, Wong GG, Moreau J, Stahl M, et al. Inhibition of pluripotential embryonic stem cell differentiation by purified polypeptides. Nature 1988;336:688-90.

[13] Hilton DJ, Gough NM. Leukemia inhibitory factor: a biological perspective. J Cell Biochem 1991;46:21-6.

[14] Mitsui K, Tokuzawa Y, Itoh H, Segawa K, Murakami M, Takahashi K, et al. The homeoprotein Nanog is required for maintenance of pluripotency in mouse epiblast and ES cells. Cell 2003;113:631-42.

[15] Chambers I, Colby D, Robertson M, Nichols J, Lee S, Tweedie S, et al. Functional expression cloning of Nanog, a pluripotency sustaining factor in embryonic stem cells. Cell 2003;113:643-55.

[16] Kleinman HK, Martin GR. Matrigel: basement membrane matrix with biological activity. Semin Cancer Biol 2005;15:378-86.

[17] Ludwig TE, Bergendahl V, Levenstein ME, Yu J, Probasco MD, Thomson JA Feeder-independent culture of human embryonic stem cells. Nat Methods 2006;3:637-46. 
[18] Franzin C, Piccoli M, Serena E, Bertin E, Urbani L, Luni C, et al. Single-cell PCR analysis of murine embryonic stem cells cultured on different substrates highlights heterogeneous expression of stem cell markers. Biol Cell 2013;105:549-60.

[19] Chowdhury F, Li Y, Poh YC, Yokohama-Tamaki T, Wang N, Tanaka TS. Soft substrates promote homogeneous self-renewal of embryonic stem cells via downregulating cell-matrix tractions. PLoS One 2010;5:e15655.

[20] Chowdhury F, Na S, Li D, Poh YC, Tanaka TS, Wang F, et al. Material properties of the cell dictate stress-induced spreading and differentiation in embryonic stem cells. Nat Mater 2010;9:82-8.

[21] Shi J, Liu L, Chen Y. Investigation of cell culture in microfluidic devices with different bi-layer substrates. Microelectron Eng 2011;88:1693-7.

[22] Arshi A, Nakashima Y, Nakano H, Eaimkhong S, Evseenko D, Reed J, et al. Rigid microenvironments promote cardiac differentiation of mouse and human embryonic stem cells. Sci Technol Adv Mater 2013;14:025003.

[23] Pillarisetti A, Desai JP, Ladjal H, Schiffmacher A, Ferreira A, Keefer CL. Mechanical phenotyping of mouse embryonic stem cells: increase in stiffness with differentiation. Cell Reprogram 2011;13:371-80.

[24] Horiuchi R, Akimoto T, Hong Z, Ushida T. Cyclic mechanical strain maintains Nanog expression through PI3K/Akt signaling in mouse embryonic stem cells. Exp Cell Res 2012;318:1726-32.

[25] Chalut KJ, Höpfler M, Lautenschläger F, Boyde L, Chan CJ, Ekpenyong A, et al Chromatin decondensation and nuclear softening accompany Nanog downregulation in embryonic stem cells. Biophys J 2012;103:2060-70.

[26] King JA, Miller WM. Bioreactor development for stem cell expansion and controlled differentiation. Curr Opin Chem Biol 2007;11:394-8.

[27] Massumi M, Abasi M, Babaloo H, Terraf P, Safi M, Saeed M, et al. The effect of topography on differentiation fates of matrigel-coated mouse embryonic stem cells cultured on PLGA nanofibrous scaffolds. Tissue Eng Part A 2012;18:609-20.

[28] Blin G, Lablack N, Louis-Tisserand M, Nicolas C, Picart C, Pucéat M. Nano-scale control of cellular environment to drive embryonic stem cells selfrenewal and fate. Biomaterials 2010:31:1742-50.

[29] Li Z, Gong Y, Sun S, Du Y, Lü D, Liu X, et al. Differential regulation of stiffness, topography, and dimension of substrates in rat mesenchymal stem cells. Biomaterials 2013:34:7616-25.

[30] Hashemi SM, Soudi S, Shabani I, Naderi M, Soleimani M. The promotion of stemness and pluripotency following feeder-free culture of embryonic stem cells on collagen-grafted 3-dimensional nanofibrous scaffold. Biomaterials 2011;32:7363-74.

[31] Braam SR, Denning C, Matsa E, Young LE, Passier R, Mummery CL. Feeder-free culture of human embryonic stem cells in conditioned medium for efficient genetic modification. Nat Protoc 2008;3:1435-43.

[32] Evans ND, Minelli C, Gentleman E, LaPointe V, Patankar SN, Kallivretaki M, et al. Substrate stiffness affects early differentiation events in embryonic stem cells. Eur Cell Mater 2009:18:1-14.

[33] Candiello J, Singh SS, Task K, Kumta PN, Banerjee I. Early differentiation patterning of mouse embryonic stem cells in response to variations in alginate substrate stiffness. J Biol Eng 2013;7:9.

[34] Scadden DT. The stem-cell niche as an entity of action. Nature 2006;441: 1075-9.

[35] Burdick JA, Vunjak-Novakovic G. Engineered microenvironments for controlled stem cell differentiation. Tissue Eng Part A 2009:15:205-19.

[36] Keung AJ, Healy KE, Kumar S, Schaffer DV. Biophysics and dynamics of natural and engineered stem cell microenvironments. Wiley Interdiscip Rev Syst Biol Med 2010;2:49-64.

[37] Pelham Jr RJ, Wang YL. Cell locomotion and focal adhesions are regulated by substrate flexibility. Proc Natl Acad Sci U S A 1997;94:13661-5.

[38] Biehl JK, Yamanaka S, Desai TA, Boheler KR, Russell B. Proliferation of mouse embryonic stem cell progeny and the spontaneous contractile activity of cardiomyocytes are affected by microtopography. Dev Dyn 2009;238:1964-73.

[39] Jeon K, Oh HJ, Lim H, Kim JH, Lee DH, Lee ER, et al. Self-renewal of embryonic stem cells through culture on nanopattern polydimethylsiloxane substrate. Biomaterials 2012;33:5206-20.
[40] Keung AJ, Asuri P, Kumar S, Schaffer DV. Soft microenvironments promote the early neurogenic differentiation but not self-renewal of human pluripotent stem cells. Integr Biol (Camb) 2012;4:1049-58.

[41] Wang LS, Boulaire J, Chan PP, Chung JE, Kurisawa M. The role of stiffness of gelatin-hydroxyphenylpropionic acid hydrogels formed by enzyme-mediated crosslinking on the differentiation of human mesenchymal stem cell. Biomaterials 2010;31:8608-16.

[42] Engler AJ, Sen S, Sweeney HL, Discher DE. Matrix elasticity directs stem cell lineage specification. Cell 2006:126:677-89.

[43] Rowlands AS, George PA, Cooper-White JJ. Directing osteogenic and myogenic differentiation of MSCs: interplay of stiffness and adhesive ligand presentation. Am J Physiol Cell Physiol 2008;295:C1037-44.

[44] Choi YS, Vincent LG, Lee AR, Dobke MK, Engler AJ. Mechanical derivation of functional myotubes from adipose-derived stem cells. Biomaterials 2012;33: 2482-91.

[45] Sørensen A, Alekseeva T, Katechia K, Robertson M, Riehle MO, Barnett SC. Long-term neurite orientation on astrocyte monolayers aligned by microtopography. Biomaterials 2007;28:5498-508.

[46] Lee MR, Kwon KW, Jung H, Kim HN, Suh KY, Kim K, et al. Direct differentiation of human embryonic stem cells into selective neurons on nanoscale ridge/ groove pattern arrays. Biomaterials 2010;31:4360-6.

[47] Zhu H, Cao B, Zhen Z, Laxmi AA, Li D, Liu S, et al. Controlled growth and differentiation of MSCs on grooved films assembled from monodisperse biological nanofibers with genetically tunable surface chemistries. Biomaterials 2011;32:4744-52.

[48] Cai L, Zhang L, Dong J, Wang S. Photocured biodegradable polymer substrates of varying stiffness and microgroove dimensions for promoting nerve cell guidance and differentiation. Langmuir 2012;28:12557-68.

[49] Jinno S, Moeller HC, Chen CL, Rajalingam B, Chung BG, Dokmeci MR, et al. Microfabricated multilayer parylene-C stencils for the generation of patterned dynamic co-cultures. J Biomed Mater Res A 2008;86:278-88.

[50] Chen AA, Underhill GH, Bhatia SN. Multiplexed, high-throughput analysis of 3D microtissue suspensions. Integr Biol (Camb) 2010;2:517-27.

[51] Wright D, Rajalingam B, Selvarasah S, Dokmeci MR, Khademhosseini A. Generation of static and dynamic patterned co-cultures using microfabricated parylene-C stencils. Lab Chip 2007;7:1272-9.

[52] Sasaki D, Shimizu T, Masuda S, Kobayashi J, Itoga K, Tsuda Y, et al. Mass preparation of size-controlled mouse embryonic stem cell aggregates and induction of cardiac differentiation by cell patterning method. Biomaterials 2009;30:4384-9.

[53] Villa-Diaz LG, Nandivada H, Ding J, Nogueira-de-Souza NC, Krebsbach PH, O'Shea KS, et al. Synthetic polymer coatings for long-term growth of human embryonic stem cells. Nat Biotechnol 2010;28:581-3.

[54] Skelley AM, Kirak O, Suh H, Jaenisch R, Voldman J. Microfluidic control of cell pairing and fusion. Nat Methods 2009:6:147-52.

[55] Giulitti S, Magrofuoco E, Prevedello L, Elvassore N. Optimal periodic perfusion strategy for robust long-term microfluidic cell culture. Lab Chip 2013;13: 4430-41.

[56] Ruiz SA, Chen CS. Emergence of patterned stem cell differentiation within multicellular structures. Stem Cells 2008;26:2921-7.

[57] Kilian KA, Bugarija B, Lahn BT, Mrksich M. Geometric cues for directing the differentiation of mesenchymal stem cells. Proc Natl Acad Sci U S A 2010;107: 4872-7.

[58] Nur-E-Kamal A, Ahmed I, Kamal J, Schindler M, Meiners S. Three-dimensional nanofibrillar surfaces promote self-renewal in mouse embryonic stem cells. Stem Cells 2006;24:426-33.

[59] Dickinson LE, Rand DR, Tsao J, Eberle W, Gerecht S. Endothelial cell responses to micropillar substrates of varying dimensions and stiffness. J Biomed Mater Res A 2012;100:1457-66.

[60] Charest JM, Califano JP, Carey SP, Reinhart-King CA. Fabrication of substrates with defined mechanical properties and topographical features for the study of cell migration. Macromol Biosci 2012;12:12-20. 